\title{
Awareness Regarding Implant Supported Dental Prosthesis; A Survey In Tertiary Care Set Up
}

\author{
Anum Baqar, Saman Hakeem, Farnaz Ilyas, Abid Mohsin, Fatima Hassan, Farah Javaid
}

\section{ABSTRACT:}

Objective: This research was aimed to assess the awareness and attitude regarding implant-retained prosthesis as the most advanced option for tooth replacement amongst residents of Karachi visiting tertiary care centre.

Methodology: This cross-sectional survey was conducted in the department of Prosthodontics at Bahria University Dental Hospital, Karachi. Undertaking the demographic characteristics of patients, the objective was to determine the awareness and attitude toward implant supported prosthesis.

Results: Amongst 380 responses retrieved, 9.8\% of respondents were aware about the dental implant treatment. While correlating awareness with demographics features, awareness statistically increased with educational level $(p=0.00)$ and occupational category $(\mathrm{p}=0.01)$ of the participants. The friends and relative $\mathrm{s}(40.5 \%)$ were the main source of information regarding dental implant treatment modality. $54.1 \%$ were unwilling to undergo treatment with dental implant whereas high cost (55.2\%)was the major limiting factor for implant treatment. 64.9\% demanded dental insurance for getting the treatment. $45.9 \%$ had no knowledge regarding maintenance of implant supported prosthesis $.73 .0 \%$ had no idea regarding longevity of dental implant where as $86.5 \%$ were unaware of it's impact on systemic health.

Conclusion: The overall awareness regarding implant supported prosthesis was found to be minimal. This underlines the need of efforts and measures that should be made to raise the awareness and thus alter attitude towards dental implant therapy. Expensive rates (55.2\%) was found to be the major limiting factor that should be relieved in the form of health insurance policies, especially in the developing countries like ours.

Keywords: Attitudes, Awareness, Missing teeth, Patients, Replacement

\section{INTRODUCTION:}

Asian population has the third highest prevalence of periodontitis which is an alarming signal for toothloss ${ }^{1}$. DMFT score increases with age, also indicating a dire need for tooth replacement at a large scale ${ }^{2}$. A detailed investigation of the National Health and Nutrition Examination Survey (NHANES) from 1999 to 2004 revealed that the individuals aged 20-34 years had $85.58 \%$ DMFT score, $35-50$ years had $94.30 \%$ DMFT level and 50-64 years aged people

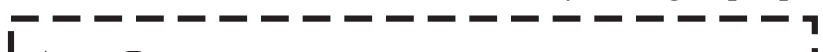

Inum Baqar,

I Senior Lecturer, Deptt. Of Prosthodontics,

I Bahria University Medical and Dental College, Karachi

I

Saman Hakeem,

Associate Professor \& HOD, Deptt. Of Prosthodontics,

I Bahria University Medical and Dental College, Karachi

I Farnaz Ilyas,

I Senior Lecturer, Deptt. Of Prosthodontics,

I Bahria University Medical and Dental College, Karachi

I Abid Mohsin,

Assistant Professor \& HOD, Community Dentistry, Mohammad Bin Qasim Medical and Dental College, Karachi I

Fatima Hassan,

Lecturer, Deptt. Of Prosthodontics,

I Bahria University Medical and Dental College, Karachi,

I Farah Javaid,

I Lecturer, Deptt. Of Prosthodontics,

I Bahria University Medical and Dental College, Karachi,

I Received: 08-01-2018

Accepted: 09-10-2018

I_Accepted: $09-10-2018$ - - - - - - - - - - J showed $95.62 \%$ DMFT grading ${ }^{2}$. Literature search shows that conventional methods of dental rehabilitation like removable dentures are unable to satisfy patient needs and demands ${ }^{3}$. That's why small number of partially and completely edentulous patients are unable to accept removable prosthesis at all due to the various factors related to anatomy, psychology and prosthodontics. Undertaking the above fact into consideration, approximately one million dental implants are inserted per year worldwide ${ }^{4}$.

Long-term clinical trials have also proven the efficacy of implant supported prosthesis. That's why dental implants emerge with universal acceptance and popularity amongst the dental community ${ }^{5}$. In 2010, Eklund SA in his paper regarding trends in dental treatment in the United States claimed increase employment of dental implant therapy ${ }^{6}$.

Pakistan's literacy rate has decreased from $60 \%$ to $58 \%$, as retrieved by the economic survey of Pakistan ${ }^{7}$. Despite of this fact, majority urban population comprising of well educated individuals, ${ }^{7}$ would consider implant supported prosthesis as a replacement option if they have the awareness of this treatment method ${ }^{8}$.

Globally, it has also been observed that knowledge regarding dental implant treatment in the developing countries is very low'. In account to the above mentioned scenario, the current investigation was carried out to assess the awareness status and thus the attitude towards implant retained prosthesis among patients visiting a tertiary care hospital in Karachi. 
Awareness Regarding Implant Supported Dental Prosthesis; A Survey In Tertiary Care Set Up

\section{SUBJECTS AND METHODS:}

This descriptive, cross-sectional study was conducted in the out patient department of Prosthodontics at Bahria University Medical and Dental College, Karachi. The duration of the study was six month sextending from June 2016 to Nov 2016. The objective was to determine the awareness and attitude towards implant supported prosthesis among population requiring tertiary management. The ethical approval was obtained from the institutional committee. WHO sample size calculator was engaged to determine the sample size at the confidence level of $95 \%$, and was found to be 380. A modified version of questionnaire was used in this study and tested on 30 patients. All subjects were interviewed using the questionnaire. It composed of demographic details, awareness status along with the resources of knowledge, various constraints in implant therapy, knowledge regarding maintenance, longevity and impact on systemic health. The inclusion criteria involved replacement seekers involving complete or partiale dentulism in any or both of the jaws. The exclusion criteria was applied on patients who were not indicated for any prosthetic rehabilitation, having dental implants previously, acquiring professional dental knowledge or unwilling to participate in the study. Descriptive analysis of the collected data was done using statistical package for social sciences version 17.0. Chi- square test was applied to establish relationship between awareness and demographic variables of the candidates. $P$ valueof $<0.05$ was considered to be significant.

\section{RESULTS:}

Three hundred and eighty patients were gauged with $47.6 \%$ male and $52.4 \%$ female patients. Regarding demographics of the candidates, $29.2 \%$ belonged to the age group of above 50 years.Majority that is $42.4 \%$ participants were illiterate. 244(64.4\%) patients belonged to the unskilled group while $136(35.6 \%)$ patients were the members of skilled group. Regarding dental status, $35.3 \%$ and $64.7 \%$ were partially edentate in the maxillary and mandibular arch respectively.

Only $9.8 \%$ had knowledge of implant supported prosthesis. While correlating dental implant awareness with the demographics, awareness statistically increased with the educational level $(\mathrm{p}=0.00)$ and category of occupation $(\mathrm{p}=0.01)$ of the participants (table-1). Friends and relatives $(40.5 \%)$ were the main source of knowledge. $54.1 \%$ were unwilling to undergo treatment with dental implant. High cost (55.2\%) was found to be the major hindrance in availing implant treatment(table -2). $64.9 \%$ demanded dental insurance for getting the treatment. $45.9 \%$ had no knowledge regarding requirement of oral hygiene of implant supported prosthesis. $73.0 \%$ had no idea regarding longevity of dental implant. $86.5 \%$ were unaware regarding impact on systemic health.

\section{DISCUSSION:}

Dental implants have been in the limelight in the field of dentistry over a decade and a half now. With improving long

\begin{tabular}{|l|c|}
\hline $\begin{array}{l}\text { Demographics Variables } \\
\text { versus implant knowledge }\end{array}$ & p- value \\
\hline Age & 0.13 \\
\hline Gender & 0.42 \\
\hline Education & 0.00 \\
\hline Occupation & 0.01 \\
\hline Dental status & 0.09 \\
\hline
\end{tabular}

$\mathrm{p}$ - value is computed via chi-square test where the significance is at 0.05 level

Table 1: Correlation of demographic features with Dental Implant Awareness Status

\begin{tabular}{|l|c|}
\hline Obstacles in availing treatment & Percentages \\
\hline High cost & $55.2 \%$ \\
\hline Confusion regarding procedure & $10.3 \%$ \\
\hline Surgery need & $10.3 \%$ \\
\hline Medical issues & $13.8 \%$ \\
\hline Others & $10.3 \%$ \\
\hline
\end{tabular}

Table 2 Hindrance factors in availing dental Implant therapy

term prognosis of implant supported prosthesis majority patients are demanding dental implants as the supreme choice for rehabilitation of missing teeth ${ }^{10}$. Implant supported prosthesis is emerging as the most advanced treatment approach to manage partial or complete edentulism ${ }^{11}$.

It enhances retention, stability, functional efficiency, quality of life and hence long-term prognosis ${ }^{12}$. The periodical need of an epidemiological survey regarding dental issues has driven this research work to be carried out. This survey was executed to assess awareness and attitude towards implant retained dental prosthesis among patients reporting to tertiary care hospital in Karachi.

The assessment tool was an adapted questionnaire to accomplish the foremost and secondary motives of the research $^{13}$. Patient's occupation was grouped into skilled and un skilled categories. Jobs such as labourers, gardeners, mechanics were placed in the un skilled while others working as engineers, doctors, inspectors were placed in the skilled group. It is the modified extract derived from the study did by Ghani $\mathrm{F}$ et $\mathrm{al}^{14}$. As the study venue was hospital setup where mostly low literacy patients reported so the preferred mode of data collection in author's point of view was indepth interview session in local language rather than proforma filled by candidates independently.

The present study reveals $9.8 \%$ awareness regarding implant supported prosthesis. Our study is in close parallelism with other Pakistani studies like Ghani Fet a ${ }^{14}(16.6 \%)$ and Sohail $\mathrm{M}$ et $\mathrm{al}^{15}(28 \%)$ However, another study conducted in Rawalpindi ${ }^{16}$, a city of Pakistan, shows awareness status of $60 \%$ which is quite better than the current investigation and 
other above mentioned national studies. Similar results observed in the international surveys did by Al- Johany $\mathrm{S}$ et $\mathrm{al}^{5}(66.4 \%), \mathrm{P}^{17}(52.6 \%)$, Tepper $\mathrm{G}^{18}(72 \%)$ and Kohli $\mathrm{S}$ et al $(56 \%)^{19}$.

This may be due to the low socioeconomic status and low literacy level of the participants as the present study's interpretation also shows the significant association of implant awareness with education and occupation variables. Saha $\mathrm{A}$ et $\mathrm{al}^{20}$ also supports the positive correlation among variables of implant awareness, education status and mode of occupation. Additionally, it also established significant association of age, gender with implant acknowledgement which contradicts to the current analysis ${ }^{20}$. Ghani $\mathrm{F}$ et al ${ }^{14}$ and Hasnain SF et $\mathrm{al}^{21}$ also signify the role of education status in acknowledgement and attitude towards implant supported prosthesis.

The current investigation reveals friends and relatives are the prime source providers followed by dental professionals. This is in close agreement with the studies did by Ghani F et $\mathrm{al}^{14}$, Qayum B et al ${ }^{22}$ Malik AS et al. ${ }^{16}$ The present study result is in contradiction with the survey did by Al- Johany $\mathrm{S}$ et $\mathrm{al}^{5}$ and Saha $\mathrm{A}$ et $\mathrm{al}^{20}$ who reported dental professionals were the main source of information followed by media about implant supported prosthesis. Al- Musawi A et al observed media dominancy in spreading dental implant awareness followed by social gatherings. ${ }^{23}$ This may be due to the general awareness gained through regular dental checkups and frequent visits to a dentist in those countries than ours.

The expensive charges followed by medical problems are the major hurdles in opting the implant supported prosthesis. This closely resembles Ghani $\mathrm{F}$ et al, ${ }^{14}$ Malik AS et al, ${ }^{16}$ Saha A et al, ${ }^{20}$ Deeb G et al ${ }^{24}$. That's why the greater number of candidates demand insurance coverage for the implant treatment in the present work. Malik A et al also claimed that $93 \%$ of the candidates of his study were of the opinion of providing insurance coverage $\mathrm{e}^{25}$. Chowdhary $\mathrm{R}$ et al also observed the similar scenario regarding insurance of dental implant treatment ${ }^{26}$.

The current study also explores the lack of knowledge regarding maintenance, longevity and the impact of dental implant therapy on systemic health. CO et $\mathrm{al}^{13}$ in his survey involving 527. Turkish adults reported $16 \%$ of the total sample population believed that their dental implants would last forever followed by longevity $>10$ years. Sawal $\mathrm{P}$ et al ${ }^{17}$ also reported the same scenario where majority (58.9\%) thought lifetime longevity of the implant treatment and the requirement of greater oral hygiene than the natural dentition.Above $90 \%$ of the respondents believed that implant retained prosthesis were very good or good, an outcome observed by Malik A et al during the investigation in natives of Lahore ${ }^{25}$. The above mentioned studies are contradictory to our work where total lack of knowledge was found. This may be due to low literacy level sample population with low socioeconomic status or lack of resources, as acquired by the sample population of the present work. The overall scenario may vary if conducted in a private setting. The lack of community awareness programs and lack of resources in the general population, as evident from this study, is the prime cause of low consumption of this treatment modality. A multicenter study with extract of the true population should be called out to validate the current results.

Hence this level of overall awareness regarding implant retained prosthesis underlines the need for putting more emphasis on the said topic to upgrade dentistry in Pakistan.

\section{CONCLUSION:}

Within the limitations of the study, the overall awareness regarding dental implant treatment was observed to be lacking. Knowledge statistically improved with the educational status and category of occupation. Friends and relatives $(40.5 \%)$ were the main source of knowledge. High cost $(55.2 \%)$ was found to be the major hindrance in availing implant treatment. To overcome the financial crisis, health insurance policies should be revised and upgraded at the government level.

\section{ACKNOWLEDGEMENT:}

None

\section{CONFLICT OF INTEREST:}

There was no conflict of interest.

\section{REFERENCES:}

1. Albandar JM, Rams TE. Global epidemiology of periodontal diseases: An overview. Periodontology 2000 2002;29:7-10

2. Maqsood S, Baber H, Abbas Z, Khan JA,KhalidM.Deciphering Possible Association of Risk Factors for Dental Caries in Pakistani Population. International Journal of Dentistry 2018:14.

3. Fiske J, Davis DM, Frances C et al. The emotional effects of tooth loss in edentulous people. Br Dent J 1998; 184: 90-93

4. Pommer B, Zechner W, Watzak G, Ulm C, Watzek G, Tepper G. Progress and trends in patients' mindset on dental implants. I: level of information, sources of information and need for patient information. Clin Oral Implants Res 2011;22(2):2239.

5. Al-Johany S, Al Zoman HA, Al Juhaini M, Al Refeai M. Dental patients' awareness and knowledge in using dental implants as an option in replacing missing teeth: A survey in Riyadh, Saudi Arabia. Saudi Dent J 2010;22(4):18.

6. Eklund SA. Trends in dental treatment, 1992 to 2007. J Am Dent Assoc. 2010; 141(4): 391-9.

7. KHAWAJA R.(2018,January). Literacy rate in Pakistan. The Nations.https://nation.com.pk/08-Feb-2018/literacy-rate-inPakistan.

8. Hosadurga R, Tenneti S, Hegde S, Kashyap RS, Kumar A. Awareness, knowledge, and attitude of patients toward dental implants: A web-based questionnaire study. J Dent Implant 2015;5:93-100

9. Mgbeokwere U, Okoye L, Ekwueme O. A Survey of the 
Knowledge of Dental Implants as a Choice in Treatment of Edentulous Jaws among Health Workers in Government Dental Clinics in Enugu. Annals of medical and health sciences research. 2011; 1(1): 91-95.

10. CM Zimmer, WM Zimmer, J Williams, J Liesener. Public awareness and acceptance of dental implants. Int $\mathrm{J}$ Oral Maxillofac Implants. 1992;7(2):228-232

11. Divya K, Sivaram G, Kumar T. Awareness is the key to acceptance of implant therapy. Indian J Oral Sci 2016;7:247

12. Zitzmann NU, Sendi P, Marinello CP. An economic evaluation of implant treatment in edentulous patients-preliminary results. Int J Prosthodont 2005;18(1):20-7

13. Tomruk CO, KayahanZO, aençiftK.Patients' knowledge and awareness of dental iplants in a Turkish subpopulation.J AdvProsthodont. 2014;6(2):133-137

14. Ghani F, Moeen F, Nisar S. Patients' Knowledge and Awareness Levels for Implant- Supported Dental Prostheses at a Teaching Dental Hospital.J Pak Dent Assoc 2013;22(2):78-83

15. Sohail M, Aslam H, Ahmed N, Faruqui S, Maqsood A, Ansari MAA, Buksh H A.Awareness, Knowledge and Reluctance Regarding Dental Implants. Donn.J. D e n t. O r a 1. Hyg. 2016;2(1): 001-004.

16. Malik AS, Ahmed W, Azad AA, Butt MM, Ahmed A, AshiqS.Knowledge and attitude of patients towards dental implant at armed forces institute of dentistry, Pakistan. Pak Armed Forces Med J 2016; 66(6):867-70.

17. Suwal P, Basnet BB, ShresthaB, Parajuli PK, Singh RK. Knowledge, attitude, and awareness regarding dental implants among patients visiting a university hospital and its teaching districts. JDI 2016;6(2):57-61.
18. Tepper G, Haas R, Mailath G, Teller C, Zechner W, Watzak G. Representative marketing-oriented study on implants in the Austrian population. I. Level of information, sources of information and need for patient information. Clin. Oral Implants Res. 2003;14(5):621-633.

19. Kohli S, Bhatia S, Kaur A, Rathakrishnan T. Patients awareness and attitude towards dental implants. Indian J Dent.2015;6(4):167-71.

20. Saha A, Dutta S, Vijaya V, Rajnikant N. Awareness among patients regarding Implants as a treatment option for replacement of missing teeth in Chattisgarh. J Int Oral Health 2013; 5(5):48-52.

21. Hasnain SF, Johansson E, Krantz G. What do young adults know about the HIV/AIDS epidemic? Findings from a population based study in Karachi, Pakistan. BMC Infect Dis. 2009;9:38

22. Qayum B, Qadeer A, Jalil H. Awareness and knowledge about dental implant in patients reporting for dental treatment to Khyber college of dentistry, Peshawar. JKCD 2016;7(1).

23. Al-Musawi A, Sharma P, Maslamani M, and Dashti M (2017). Public Awareness and Perception of Dental Implants in Randomly Selected Sample in Kuwait. J Med Imp Surg 2: 116.

24. Deeb G, Wheeler B, Jones M, Carrico C, Laskin D, Deeb JG. Public and Patient Knowledge About Dental Implants. J Oral Maxillofac Surg. 2017; 75(7):1387-1391.

25. Malik A, Afridi AM, Ehsan A. Knowledge perception and choice of dental implants as a treatment option for patients visiting the university college of dentistry Lahore-pakistan. Pak Oral Dent J 2014;34(3): 560-3.

26. Chowdhary R, Mankani N, Chandraker NK. Awareness of dental implants as a treatment choice in urban Indian populations. Int J Oral Maxillofac Implants 2010;25:305-8. 